\title{
Evaluation of the effect of Gallic acid against carbon tetrachloride- induced liver injury in albino rats: histological, immunohistochemical and biochemical study
}

\author{
Original Safaa S. Hassan ${ }^{1}$, Mohammed H. Elbakry', Safwat A. Mangoura ${ }^{3}$ and Zainab M. \\ Article \\ Omar $^{4}$ \\ ${ }^{1}$ Department of Histology, Faculty of Medicine, Assiut University, Assiut, Egypt. \\ 2,4 Department of Pharmacology, Faculty of Medicine, Al-Azhar University, Assiut, Egypt \\ ${ }^{3}$ Department of Pharmacology, Faculty of Medicine, Assiut University, Assiut, Egypt
}

\begin{abstract}
Introduction: Carbon tetrachloride (CCL4) is used for induction of liver fibrosis. Liver fibrosis has no standard treatment. Gallic acid (GA) is a naturally occurring phenolic compound having anti-inflammatory and anti-cancer activities.

Aim of the work: This work aimed to evaluate the preventive role of GA against CCL4 induced liver fibrosis.

Materials and Methods: Forty adult male albino rats were divided into 4 groups; Group I: without treatment .GroupII: received olive oil. Group III: received $1.5 \mathrm{~mL} / \mathrm{kg}$ of CCL4 twice a week. Group IV: received CCL4 with GA $100 \mathrm{mg} / \mathrm{kg}$. Animals were sacrificed after 8 weeks. Liver specimens were processed for light and electron microscopic (EM) study. Area \% of collagen and $\alpha$-SMA expression, levels of AST, ALT, ALP, reduced GSH, MDA, SOD and hydroxyproline were measured and evaluated statistically.

Results: Group III revealed foci of altered hepatocytes with dense nuclei and vacuolated cytoplasm. Dilatation and congestion of central and portal veins with mononuclear cell infiltration were observed. There was increased collagen deposition around the central vein. Intense stained $\alpha$-SMA-positive cells were observed. CCL4 increased collagen and $\alpha$-SMA expression area $\%$. EM showed electronlucent areas in the cytoplasm of the hepatocytes, vacuolation and margination of nuclear chromatin. CCL4 increased AST, ALT, ALP, hepatic MDA and hydroxyproline levels. Moreover, it decreased the activities of SOD and reduced GSH. The co-administration of GA prevented most of these histological and biochemical changes.

Conclusions: The use of natural antioxidants as GA can be promising in ameliorating liver fibrosis better than the drugs and their side effects.
\end{abstract}

Key Words: Antioxidant, CCL4, gallic acid, liver fibrosis.

Revised: 3 January 2018, Accepted: 4 March 2018

Corresponding Author: Safaa Said Hassan, PHD, Department of Histology and cell biology, Faculty of Medicine, Assiut University, Assiut, Egypt, Tel.: 01090067886, E-mail: Hassan.safaa@yahoo.com

ISSN: 2536-9172, Vol.1, No.2

\section{INTRODUCTION}

Liver is an important organ which is actively included in many metabolic activities. It is the frequent target for many toxicants. Hepatic damage is associated with distortion of its metabolic activities. Uncontrollable remodeling and regeneration would lead to the development of fibrosis due to excessive deposition of extracellular matrix (ECM). The remodeling of ECM during chronic liver diseases might be attributed to the altered activity of matrix metalloproteinases-2 (MMP-2). The increase in MMP-2 causes damage to the membrane in the space of Disse, this activates hepatic stellate cell (HSC) and induces hepatic fibrogenesis ${ }^{[1]}$.

Carbon tetrachloride (CCl4) was widely used as solvent for oil, drug against hookworm, anesthetics and analgesics. It is a highly toxic chemical agent that causes hepatic toxicity. Prolonged administration of $\mathrm{CCl} 4$ causes fibrosis, centrolobular necrosis, cirrhosis and hepatic carcinoma $^{[2]}$. Oxidative stress could be an important factor in the pathogenesis of CCl4-induced liver injuries. Carbon tetrachloride induced hepatic injury is a well-established animal model of liver fibrosis, as rats hepatic responses to chronic $\mathrm{CCl} 4$ administration are similar to human fibrosis $^{[3]}$.

The treatment of hepatic fibrosis by synthetic drugs might be effective but dangerous as the liver is the final target for drug metabolism. Antioxidants play an essential role in hepatoprotective activity. So, in the present times, the search for crude drugs of natural origin with antioxidant activity has become a mandatory focus of the hepatoprotection researches. As, drugs of natural origin cause perfect curative action without any side effects ${ }^{[4]}$.

Now there is an increasing interest in phytoconstituents, especially phenolic compounds, due to their 
beneficial effects on disease prevention and longevity ${ }^{[5]}$. Gallic acid (GA) is a type of organic acid and a naturally occurring phenolic compound. It is also known as 3, 4, 5 -trihdroxybenzoic acid ${ }^{[6]}$. It is an important component of iron gallic ink. George Washington used gallic acid to communicate with spies during $\operatorname{war}^{[7]}$. As gallic acid has limited distribution in food, this resulted in limited interest by nutritionists. Gallic acid is abundant in natural plants such as gallnuts, grapes, sumach, oak bark, green tea, apple peels, strawberries, pineapples, banana, and lemon. It was found that a high percentage of GA present in at least thirty herbs and their formulations used in Asian sub-continent for treatment of several diseases ${ }^{[8]}$. Very little is known about the absorption and metabolism of hydroxybenzoic acid. However, the few researches that studied the bioavailability of gallic acid in humans revealed that it is well absorbed ${ }^{[9]}$.

The aim of the present study was to evaluate the preventive role of gallic acid against carbon tetrachloride induced liver histological and biochemical changes, and discuss its possible mechanisms of action.

\section{PATIENTS AND METHODS}

\section{Chemicals}

CCL4 was purchased from El-Naser Pharmaceuticals chemical company, Egypt, and Gallic acid from Oxford Laboratory, Mumbai, India.

\section{Animals}

A total number of forty adult male albino rats, aged 3 months, were used. The weight range of the rat was 200-250gm. The animals were maintained in the Animal House in Assiut University under normal conditions with an appropriate temperature, fed rat chow and allowed free access of water.

The animals were divided into four equal groups (10 rats each):

Group I: rats were kept without treatment for 8 weeks

Group II: rats received olive oil subcutaneous injection twice a week for 8 weeks.

Group III: received subcutaneous injection of $1.5 \mathrm{~mL} /$ $\mathrm{kg}$ of CCL4 diluted with olive oil (50:50) twice a week for 8 weeks (10).

Group IV: subjected to the same dose of CCL4 as group II and co-treatment with Gallic acid $100 \mathrm{mg} / \mathrm{kg}$, orally, daily for 8 weeks (11).

Forty-eight hours after the last $\mathrm{CCl} 4$ injection, rats were sacrificed.

\section{Histological examination:}

At the end of the study, the animals were anesthetized with ether, their hearts were exposed and perfused with saline and $10 \%$ formalin until the flowing blood was cleared.

\section{Light microscopic staining:}

Small pieces of the liver tissues were randomly cut from at least 2 different lobes. The liver specimens were fixed in $10 \%$ neutral formalin and processed to form paraffin sections $(5 \mu \mathrm{m})$ stained with haematoxylin and Eosin (Hx\&E) and Masson's Trichrome.

\section{Immunohistochemical staining:}

Liver Paraffin sections were immunohistochemically stained to detect $\alpha$-SMA, an indicator of HSCs activation. The sections were first incubated at $37^{\circ} \mathrm{C}$ for 30 minutes, then, deparaffinized, embedded in xylene and gradually hydrated with descending grades of ethanol. After these the samples were washed in purified water. After several washes in washing buffer (phosphate buffered saline [PBS], the sections were blocked with peroxidase blocking solution for 10 minutes at room temperature and were then washed in washing buffer. Next, sections were blocked with blocking serum for 30 minutes at room temperature and rinsed with PBS. Afterwards, sections were incubated with $\alpha$-SMA $(1: 200)$ (thermo, scientific:USA) at $4 \mathrm{C}$ overnight. After several washes with washing buffer, the sections were incubated with secondary antibody horseradish peroxidaseconjugated immunoglobulin G (Boster Biotechnology), for $30 \mathrm{~min}$ at $37^{\circ} \mathrm{C}$ and rinsed with washing buffer. The sections were visualized with a DAB chromogen solution and counterstained lightly with hematoxylin. Finally, the sections were gradually dehydrated in ethanol, cleared using xylene and mounting.

\section{Morphometric measurements}

(1) Mean area \% of collagen fibers was measured using imageJ ${ }^{\circledR}$ software (National Institutes of Health, Bethesda,USA). The measurements were done at $400 \mathrm{X}$ magnification in 6 fields of the liver sections stained by Masson's Trichrome in five animals from each group.

(2) Mean area $\%$ of $\alpha$-SMA expression was estimated in positive cells using imageJ ${ }^{\circledR}$ software (National Institutes of Health, Bethesda, USA). The measurements were done at $400 \mathrm{X}$ magnification in 6 fields of the liver $\alpha$-SMA immunostained sections in five animals from each group.

\section{Electron microscopic staining:}

Specimens $(1 \mathrm{~mm})$ size were taken from liver and fixed with $2.5 \%$ buffered glutaraldehyde at $4^{\circ} \mathrm{C}$ for $2 \mathrm{~h}$ and post fixed in osmium tetraoxide for one hour. Semithin sections 
$(0.5 \mu \mathrm{m})$ were cut, stained with toluidine blue (T.B) and examined with light microscope. Ultrathin sections (80-90 $\mathrm{nm})$ were cut form the selected areas in semithin section, stained with lead citrate and uranyl acetate, examined and photographed with transmission electron microscope. JEOL (J.E.M.-100 CXII) in Assiut University / Electron Microscope Unit.

\section{Biochemical measurements}

1-Blood samples were collected by retro-orbital puncture (from optic vein), and centrifuged at $3000 \mathrm{rpm}$ for $15 \mathrm{~min}$. The serum was kept in the deep freezer at $\left(-20^{\circ} \mathrm{C}\right)$ until analyzed for liver enzymes activities ALT, AST, ALP by Colorimetric methods. The intensity of the color produced is directly proportional to the enzymatic activity (12).

2-Liver specimens were immediately excised. About $1 \mathrm{gm}$ of each frozen specimen was homogenized by ultra sonic homogenizer in $9 \mathrm{ml}$ ice-cold phosphate bufferd saline (PBS) to obtain $10 \%(\mathrm{w} / \mathrm{v})$. The resultant supernatant was stored at $-20^{\circ} \mathrm{C}$ until used for determination of reduced GSH, MDA, SOD and hydroxyproline concentration ${ }^{[13]}$.

\section{Statistical analysis}

Biochemical and morphometric results were expressed as means \pm standard deviation (SD) of each group and statistically analyzed using SPSS (Version 16; SAS Institute Inc., Cary, North Carolina, USA). One way ANOVA test was employed to compare the studied animal groups. The statistical significance level was set at $P<0.05$.

\section{RESULTS}

\section{Histological results:}

\section{(A) Light microscopic examination}

Light microscopic examination of liver sections stained with H\&E of the control groups (GI, II) showed normal hepatic lobules architecture. They are formed of hepatocytes arranged in cords radiating from central vein to the periphery of the lobules and separated by blood sinusoids (Fig.1a\&b). Hepatocytes appeared polyhedral with granular acidophilic cytoplasm and central rounded pale nuclei with prominent nucleolus; some of the hepatocytes are binucleated. Sinusoids lined with flattened endothelial cells (Fig. 2a\&b).

In CCL4 treated group (III) liver sections showed obvious changes with distortion of lobular architecture. These changes were noted in the form of patches of cellular degeneration through the lobules. Some of altered cells showed dense nuclei and vacuolated cytoplasm, others had deeply stained cytoplasm and lost their nuclei. There were patches of mononuclear cellular infiltrations in between degenerated hepatocytes and in the portal areas. Vascular dilatation and congestion were observed in the portal areas and in the central veins (Fig.3a\&b). The affected cells showed foamy vacuolated cytoplasm, dense nuclei and nuclear shrinkage. In semithin sections, there was vacuolar cytoplasmic degeneration of hepatocytes. Some cells had greatly disintegrated karyolytic nuclei. Some hepatocytes contained dark granules in their cytoplasm (Fig.4a\&b).

In combined $\mathrm{CCl} 4$ and Gallic acid co-treated group light microscopic examination of liver sections revealed less degenerative changes. The liver lobules regained their regular architecture, some hepatocytes preserved normal appearance, other showed reduction in hepatic lesions. Still some hepatocytes showed increased cytoplasmic acidophilia. The degree of vascular congestion and inflammatory cellular infiltration appeared to be decreased. Sinusoids were lined with flattened endothelial cells (Fig.5a\&b). Some hepatocytes with central rounded vesicular nucleus were seen. Some blood sinusoids were dilated. In semithin section apparently normal polyhedral hepatocytes with granulated cytoplasm and large rounded nuclei with prominent nucleoli were noticed. Binucleated cells were observed, some cells showed vacuolation (Fig.6a\&b).

Masson's trichrom stained sections of control groups (GI, II) showed scanty amount of collagen fibers around the central vein (Fig.7). While, CCL4 treated group (III) showed apparently excess amount of collagen fibers around the central vein (Fig.8). In combined $\mathrm{CCl} 4$ and Gallic acid co-treated group Masson's trichrom stained sections showed scanty amount of collagen fibers around the central vein (Fig.9).

\section{Immunohistochemical results:}

$\alpha$-SMA positive cells were observed in central vein only in control group( GI, II) (Fig.10). More intense staining $\alpha$-SMA-positive cells occupied most of the liver fibrous tissue around central vein and portal tract in CCL4 treated group (Fig.11). $\alpha$-SMA positive staining was apparently decreased in rats given Gallic acid. It was more or less similar to control group (Fig.12).

\section{Morphometric results:}

(1) Statistical analysis of collagen area \% showed significant increase in the mean area \% in CCL4 treated rats as compared to control group. Gallic acid induced a significant reduction in the mean collagen area $\%$ as compared to CCL4 group (table 1).

(2) Analysis of $\alpha$-SMA expression area $\%$ showed that CCL4 significantly increased $\alpha$-SMA expression area $\%$ as compared to control group. Treatment with gallic acid significantly decreased $\alpha$-SMA expression area $\%$ as compared to CCL4 group (table 1). 


\section{(B) Electron microscopic results:}

Electron microscopic examination of hepatocytes of control groups (GI, II) showed hepatocyte with large round euchromatic nucleus and prominent nucleolus. The cellular organelles were uniformly distributed throughout the cytoplasm. Numerous mitochondria, cisternae of rough endoplasmic reticulum, SER and numerous glycogen granules were noted (Fig. 13). Electron microscopic examination of hepatocytes CCL4 treated group (III) revealed hepatocyte with many electron lucent areas of the rarified cytoplasm which contained electron dense organelles, mitochondria and dispersed glycogen granules. The nuclei were variable in size and showed peripheral localization of heterochromatin clumps (Fig. 14).Electron microscopic examination of combined $\mathrm{CCl} 4$ and Gallic acid co-treated group revealed reduction in the structural impairment. Most of hepatocytes regained their normal structure, with fine distribution of the chromatin and prominent nucleolus, however electron lucent areas were observed in the cytoplasm of some hepatocytes. The mitochondria seemed to be normal but with electron dense matrix and intact cisterna. Numerous rER and glycogen granules were seen (Fig. 15).

\section{Biochemical results:}

Statistical analysis of biochemical assay regarding ALT, AST and ALP showed highly significant increase in these liver enzymes $(\mathrm{P}<0.01)$ in CCL4 group compared to control group. A significant decrease $(\mathrm{P}<0.01)$ was obtained in these liver enzymes after gallic acid coadministration (table 2, chart 1).

Also there was highly significant change $(\mathrm{P}<0.01)$ on oxidative stress markers. A significant increase in MDA level, and decrease in GSH and SOD levels of CCL4 injected rats as compared to control group were detected. There was highly significant decrease in MDA level and increase in GSH and SOD level $(\mathrm{P}<0.01)$ in livers in rats co-treated with gallic acid when compared to CCL4 group. There was marked increase in hydroxyproline content in liver treated with CCL4 compared to control group. Co-administration of Gallic acid significantly decrease $(\mathrm{P}<0.01)$ hydroxyproline content of Gallic acid treated rats (table 3 , chart 2 ).

Table (1): Mean collagen area $\%$ and Mean $\alpha$ SMA area $\%$ in experimental groups:

\begin{tabular}{lcc}
\hline groups & Mean collagen area $\%$ & Mean $\alpha$ SMA area $\%$ \\
\hline control & $2.598 \pm .374$ & $1.028 \pm .023$ \\
CCL4 & $10.028 \pm 1.83 * *$ & $1.028 \pm .023$ \\
GA & $5.448 \pm .693^{*}$ & $1.325 \pm .093^{*}$ \\
\hline
\end{tabular}

Results are presented as mean \pm SD.

** Highly significant

*Significant

Table (2): serum ALT, AST and ALP in experimental groups:

\begin{tabular}{llll}
\hline groups & ALT & AST & ALP \\
\hline control & $36 \pm 1.9$ & $103.33 \pm 1.7$ & $99 \pm 2.8$ \\
CCL4 & $355.67 \pm 43^{* *}$ & $698.11 \pm 73^{* *}$ & $921.11 \pm 53.4^{* * *}$ \\
Gallic acid & $200.76 \pm 6.5^{* *}$ & $495 \pm 14.53^{*}$ & $588 \pm 19.53^{*}$ \\
\hline
\end{tabular}

Results are presented as mean \pm SD.

** Highly significant

*Significant

Chart (1): serum ALT, AST and ALP in experimental groups:

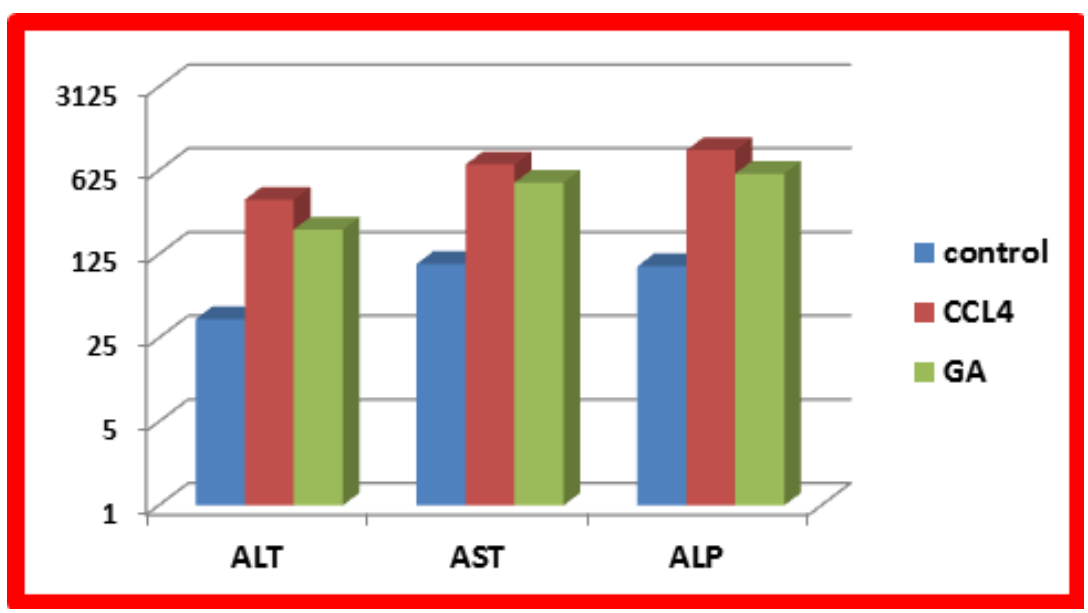


Table (3): hepatic MDA, GSH, SOD and hydroxyproline in experimental groups:

\begin{tabular}{lllll}
\hline Group & $\begin{array}{l}\text { MDA }(\mathrm{nmol} / \mathrm{gm} / \mathrm{dry} \\
\text { tissue) }\end{array}$ & GSH (mg/gm/dry tissue) & SOD (U/gm dry tissue) & $\begin{array}{l}\text { Hydroxyproline } \\
\text { dry tissue) }\end{array}$ \\
\hline control & $45.36 \pm 0.9$ & $11.05 \pm 0.47$ & $25.37 \pm 1.8$ & $58 \pm 1.37$ \\
CCL4 & $97.93 \pm 2.6^{* *}$ & $4.44 \pm 0.39^{* *}$ & $10.78 \pm 0.9^{* *}$ & $228.66 \pm 1.16^{* *}$ \\
Gallic acid & $68.04 \pm 0.87^{* *}$ & $6.5 \pm 0.27^{*}$ & $18.74 \pm 0.50 * *$ & $166.16 \pm 6.02^{* *}$ \\
\hline
\end{tabular}

Results are presented as mean $\pm \mathrm{SD}$

** Highly significant

*Significant

Chart 2: hepatic MDA, GSH, SOD and hydroxyproline in experimental groups:
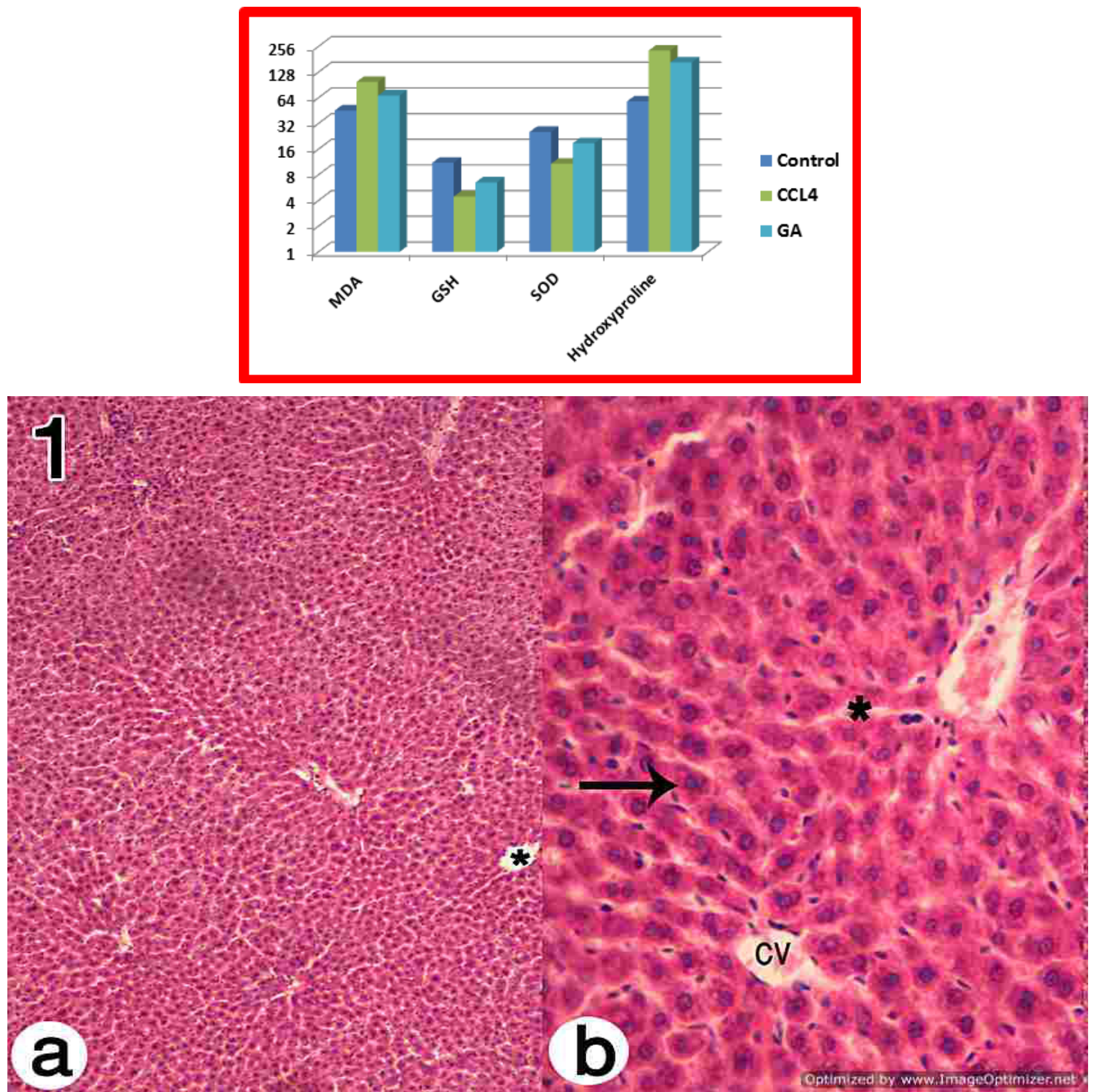

Fig. 1 (1a): A photomicrograph of a section in the liver of control groups showing; the normal architecture of tightly packed cords of hepatocytes around centrilobular vein $(*)$.

(H\&E, X100).

(1b) Higher magnification showing radiating irregular anastomosing plates of hepatocytes with vesicular nuclei ( $\uparrow)$, intervening blood sinusoids $(*)$ and central vein $(\mathrm{cv})$.

$(\mathrm{H} \& \mathrm{E}, \mathrm{X} 400)$ 


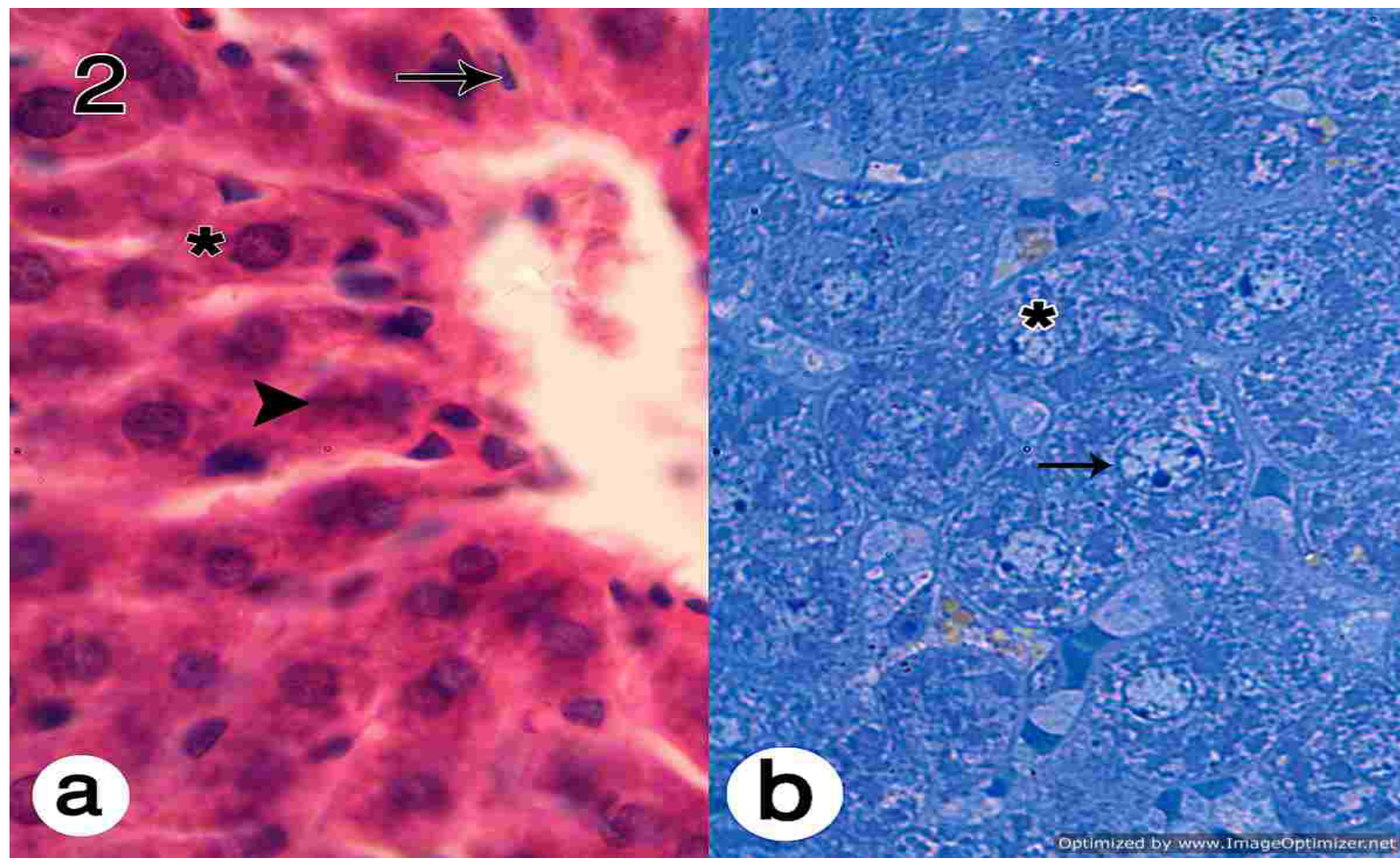

Fig.2 (2a): A photomicrograph of a section in the liver of control groups showing; the hepatocytes with granular acidophilic cytoplasm $(\Delta)$ and central rounded nuclei $(*)$. Blood sinusoids lined with flattened endothelial cells $(\uparrow)$.

$(\mathrm{H} \& \mathrm{E} X 1000)$ (2b): Semithin section of control groups showing; the polyhedral hepatocytes with granulated cytoplasm and rounded nuclei with prominent nucleoli $(\uparrow)$. Some hepatocytes are binucleated $(*)$.

(T.B X1000)

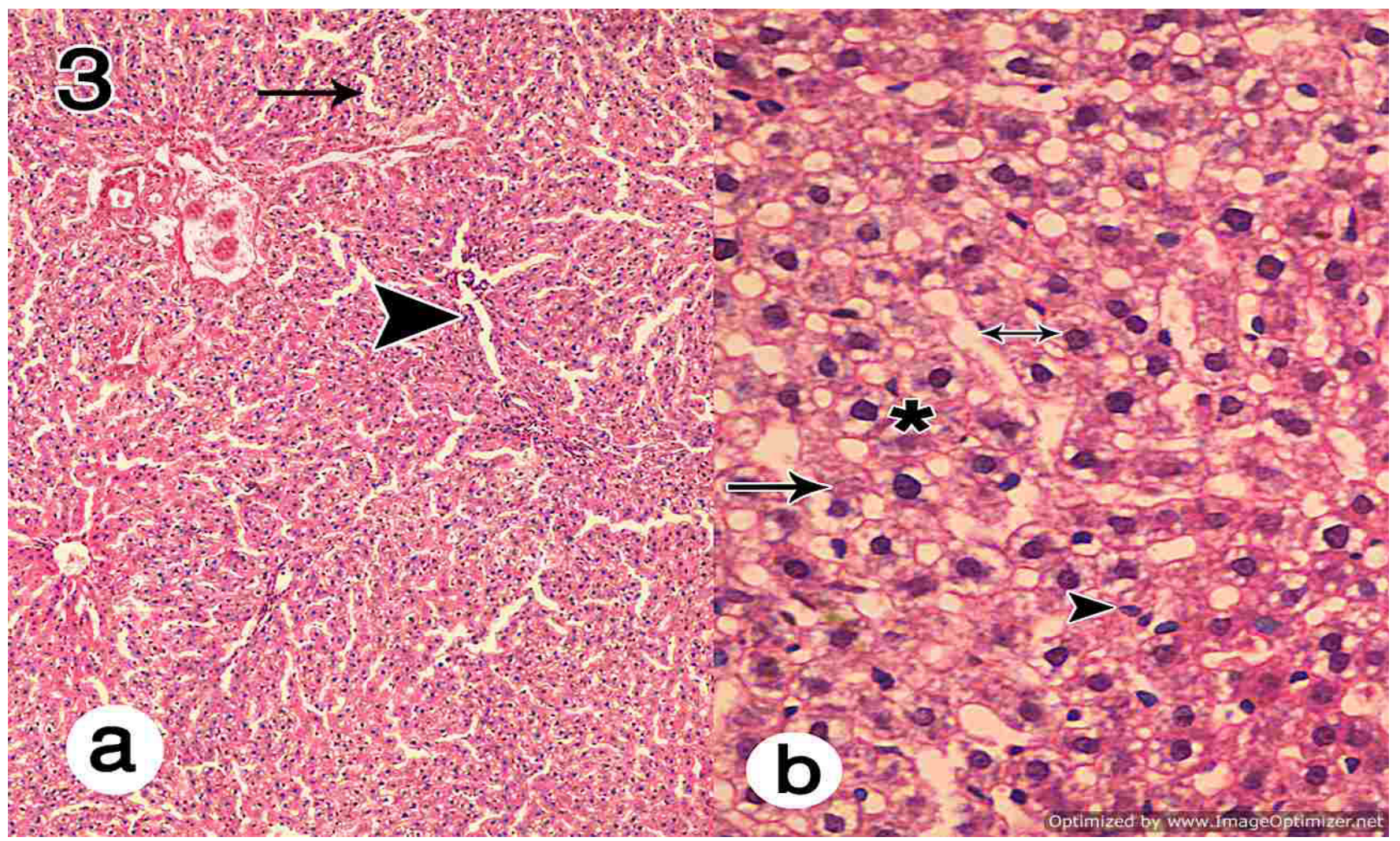

Fig. 3 (3a): A photomicrograph of a section in the liver of CCL4 group showing distortion of lobular architecture ( $\uparrow$ ) and dilated blood sinusoids $(\Delta)$.

(H \& E X 100)

(3b): Showing hepatocytes with pyknotic nuclei $(*)$, other lost their nuclei with deeply stained cytoplasm $(\uparrow)$. Notice inflammatory cellular infiltration and congestion in between degenerated hepatocytes $(\Delta)$ and dilated blood sinusoids $(\uparrow)$.

$(\mathrm{H} \& \mathrm{E} X 400)$ 


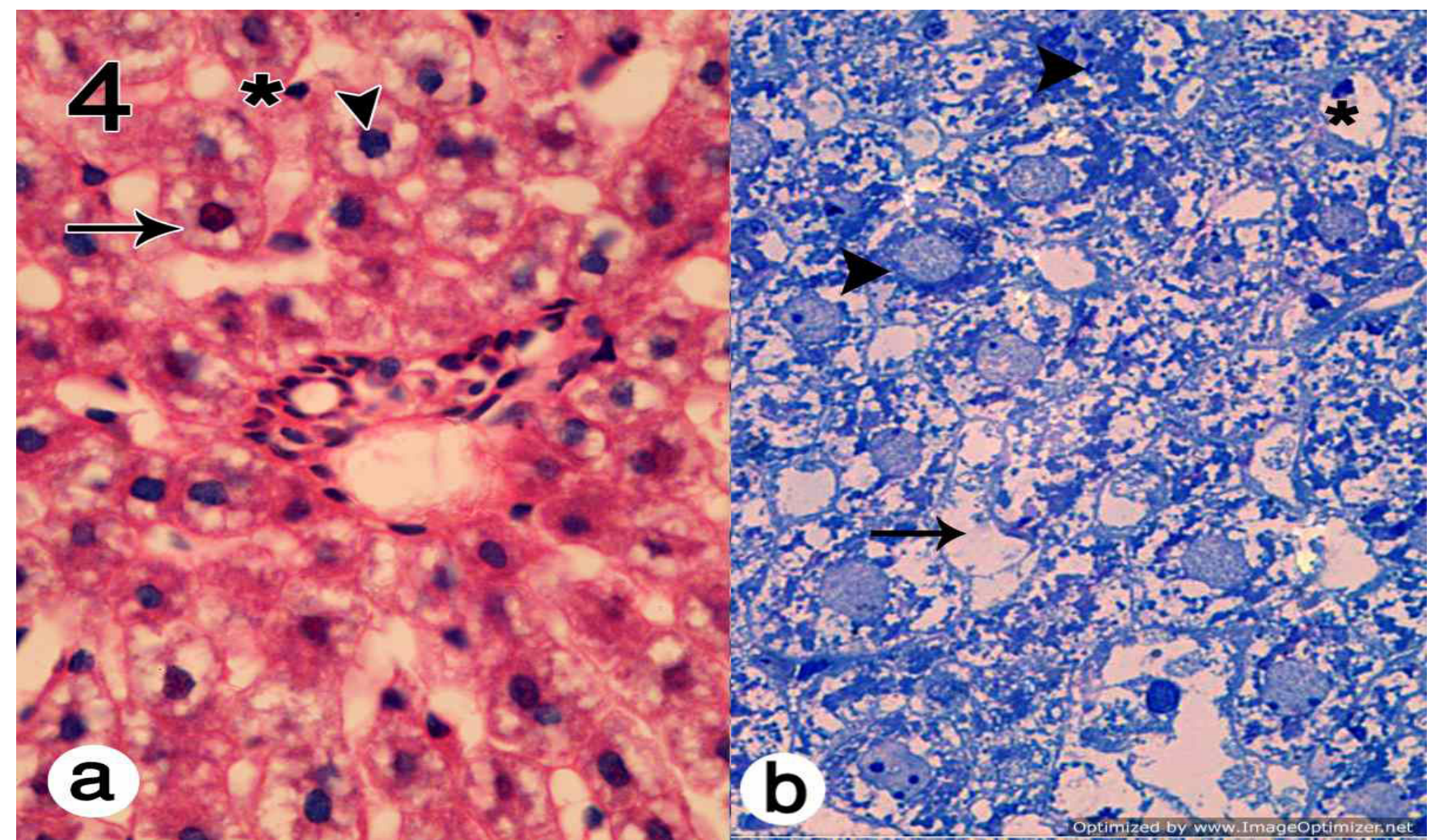

Fig. 4 (4a): A photomicrograph of a section in the liver of CCL4 group showing, foamy vacuolated cytoplasm of the affected cells ( $\uparrow$ ), dense nucleus $(\Delta)$ and nuclear shrinkage $(*)$.

(H\&E X1000)

(4b): Semithin section showing, degeneration of hepatocytes $(\uparrow)$, massive vacuolar cytoplasmic degeneration and necrosis in

hepatocytes $(\uparrow)$ and some cells had karyolytic nuclei $(*)$. Notice, some hepatocytes contained dark graules in their cytoplasm $(\Delta)$.

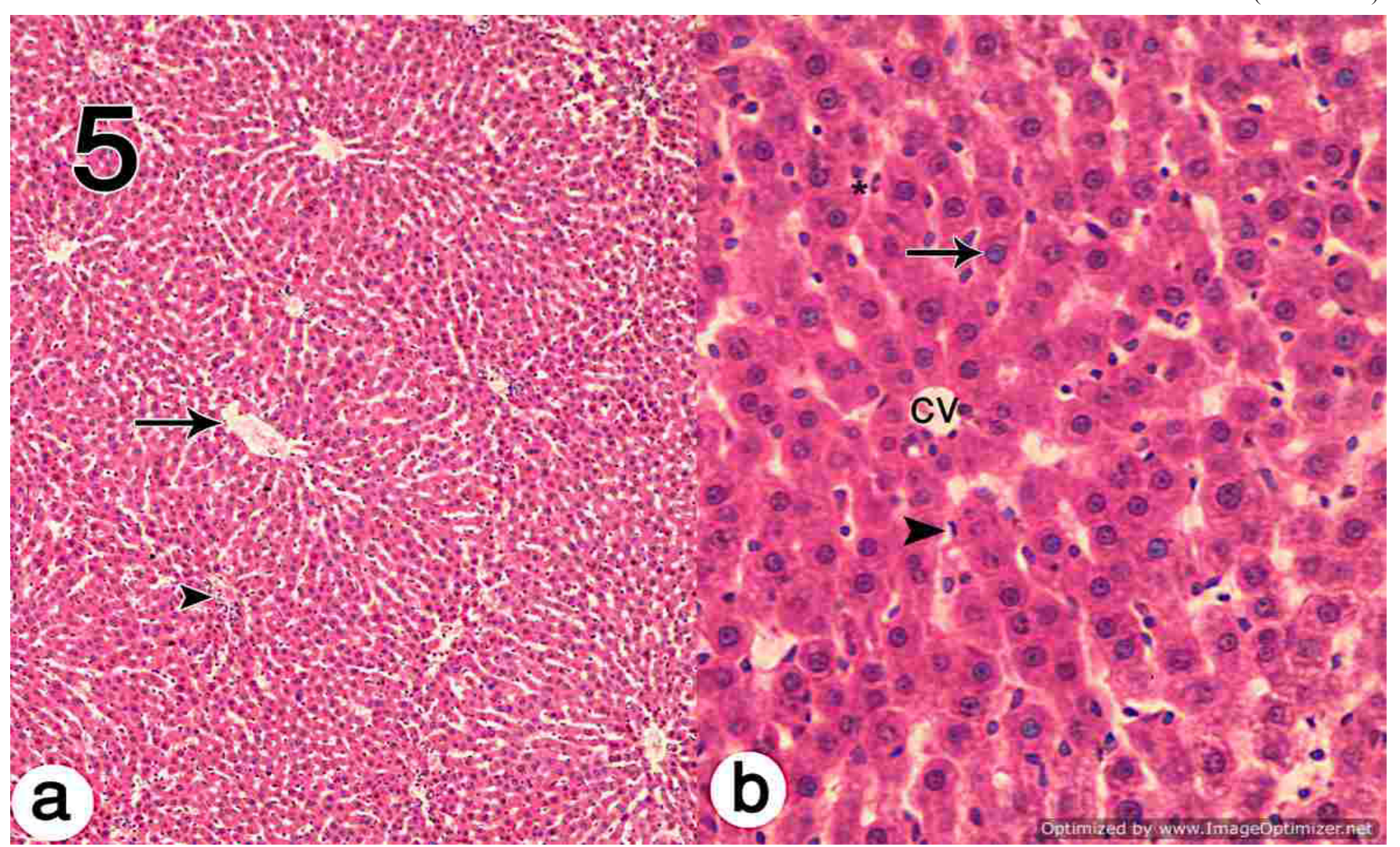

Fig. 5 (5a): A photomicrograph of a section in the liver of combined CCl4 and GA group showing; liver cell cords formed of normal hepatocytes. Notice, mild vascular congestion $(\uparrow)$ and inflammatory cellular infiltration $(\Delta)$. (H\&E X 100). $(5 \mathrm{~b})$ : Showed that some hepatocytes had increased cytoplasmic acidophilia $(*)$. Notice plates of hepatocytes with vesicular nuclei $(\uparrow)$, intervening blood sinusoids lined with flattened endothelium $(\Delta)$ and central vein $(\mathrm{cv})$.

(H\&E X 400) 


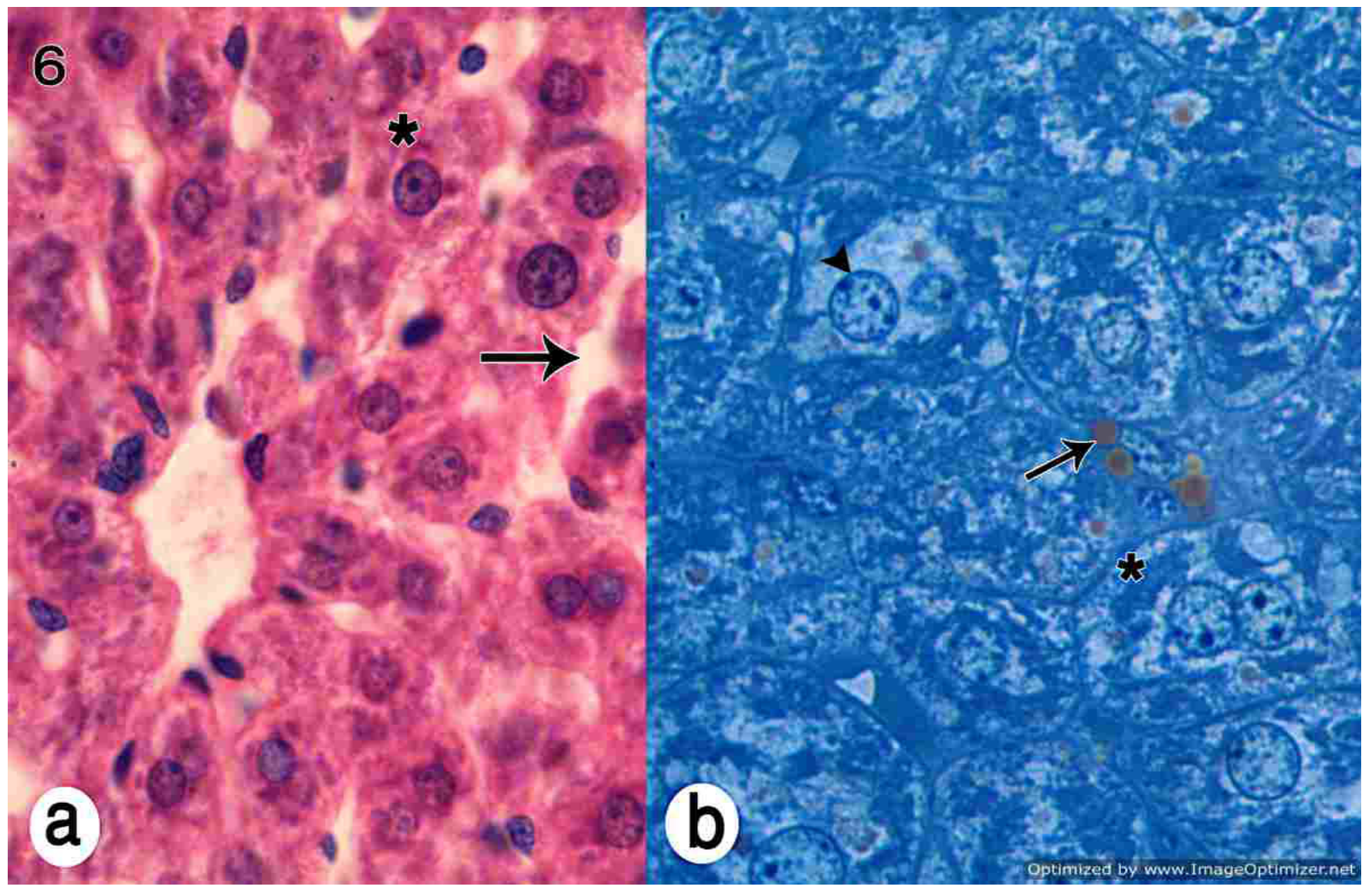

Fig. 6 (6a): A photomicrograph of a section in the liver of combined CCl4 and GA group showing; some hepatocytes with central rounded vesicular nucleus $(*)$. Some blood sinusoids are dilated $(\uparrow)$. (H\&E X 1000) (6b): Semithin section showing apparently normal polyhedral hepatocytes with granulated cytoplasm, large rounded nuclei with prominent nucleoli $(\Delta)$ and lipid droplet $(\uparrow)$. Binucleated cells were observed $(*)$.

(T.B X1000)

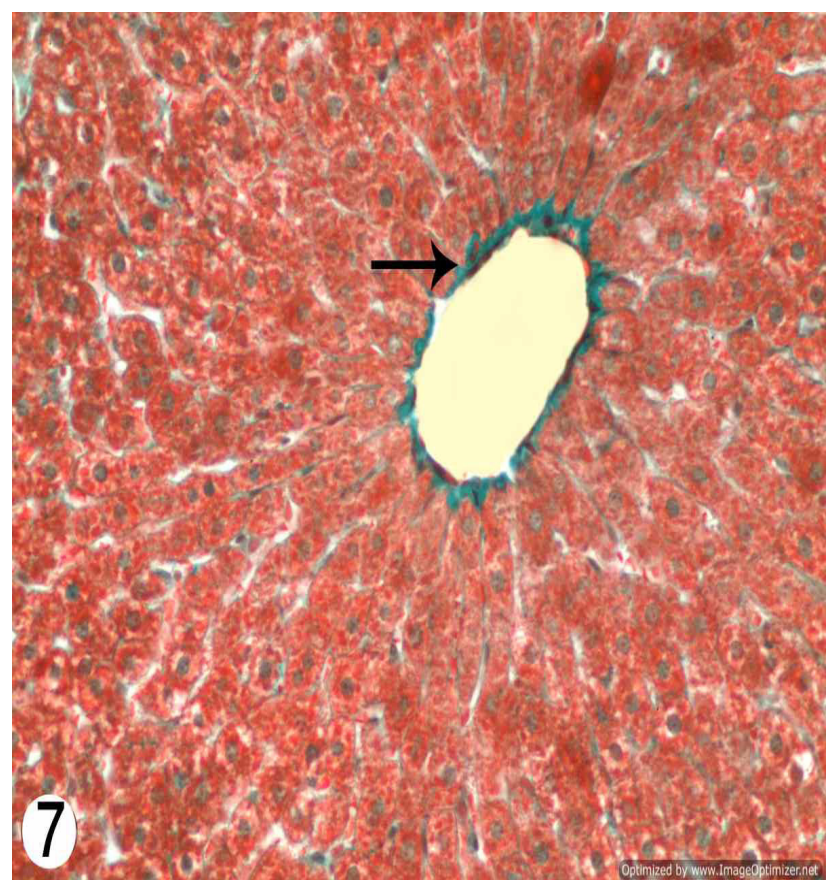

Fig. 7: A photomicrograph of a section in the liver of control group showing; scanty amount of collagen fibers around the central vein $(\uparrow)$.

Trichrome X400).
(Masson's

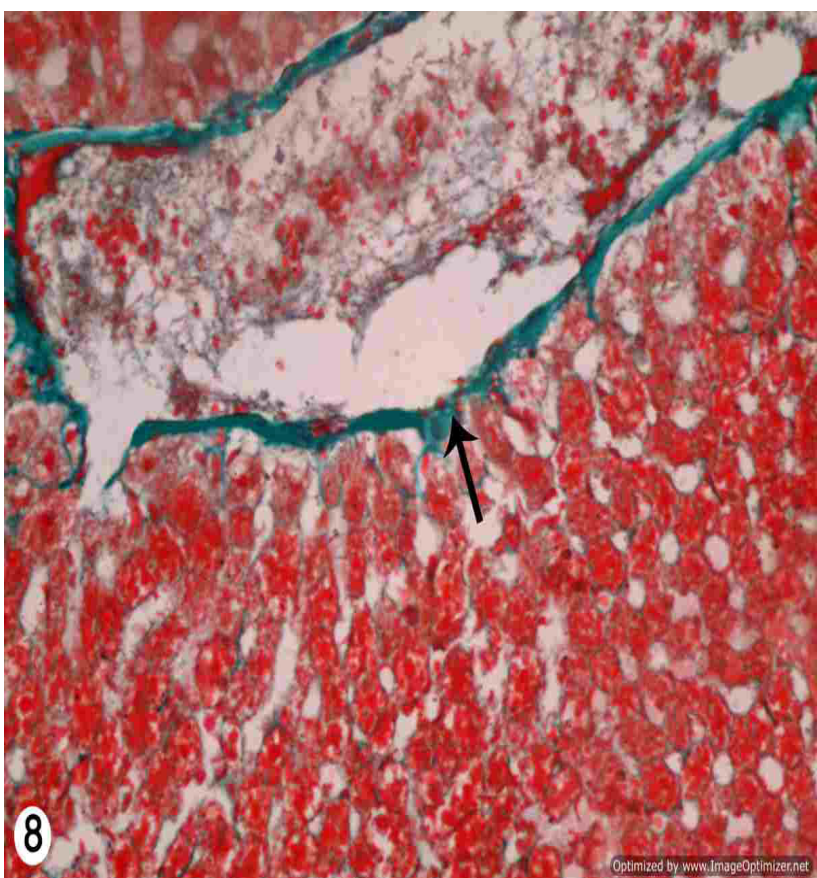

Fig.8: A photomicrograph of a section in the liver of CCL4 group showing: marked deposition of fibrous tissue around the centra $\operatorname{vein}(\uparrow)$. (Masson's Trichrome X400). 


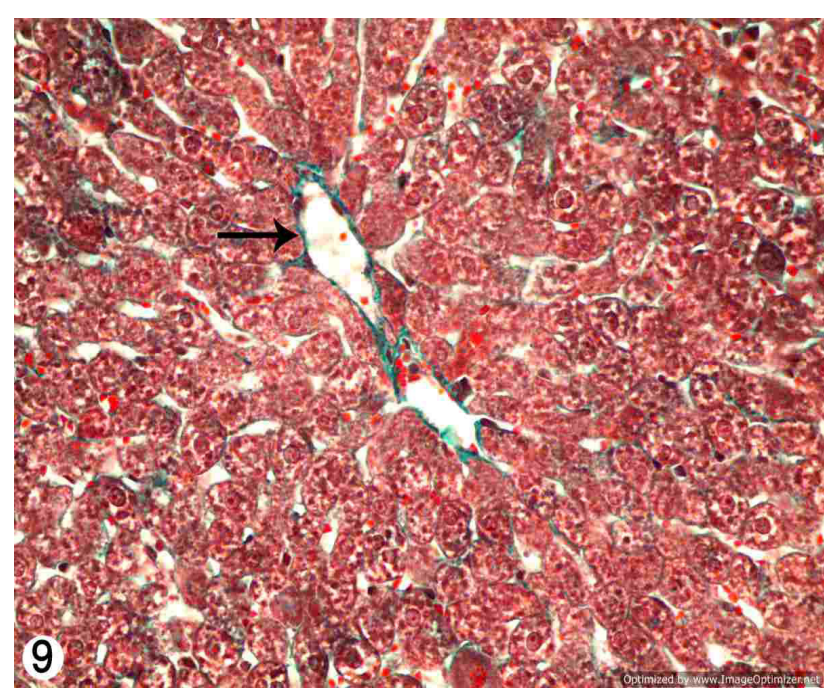

Fig. 9: A photomicrograph of a section in the liver of combined $\mathrm{CCl} 4$ and GA group showing; scanty amount of collagen fiber located mainly around the central vein ( $\uparrow)$.

(Masson's Trichrome X400).

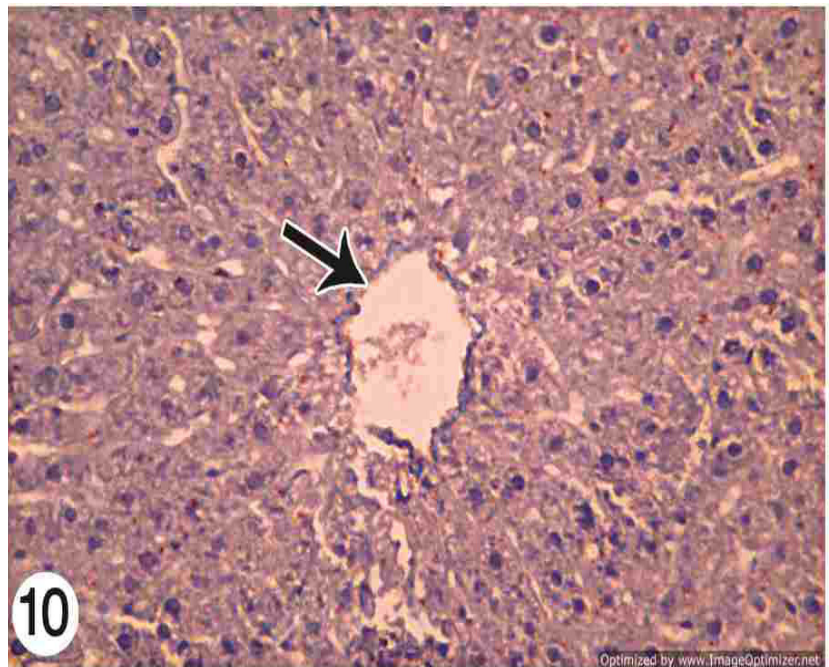

Fig. 10: A photomicrograph of a section in the liver of control group showing; $\alpha$-SMA-positive cells (brown color) are restricted to the central vein only $(\uparrow) . \quad(\alpha$-SMA Immunostaining, X400).

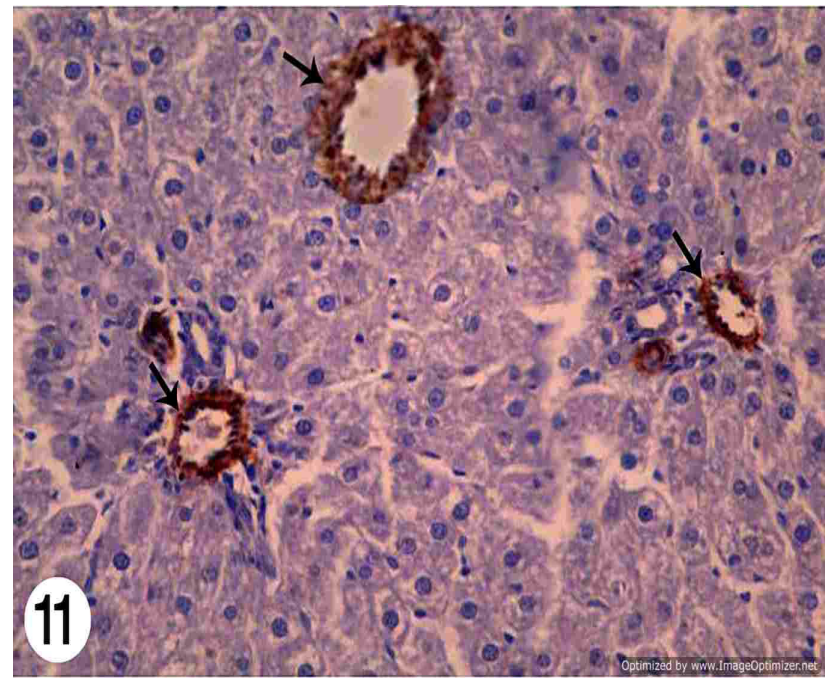

Fig. 11: A photomicrograph of a section in the liver of CCl4 group showing; intense $\alpha$-SMA staining in the liver around central vein and portal tract $(\uparrow)$. $(\alpha$-SMA Immunostaining, X400).

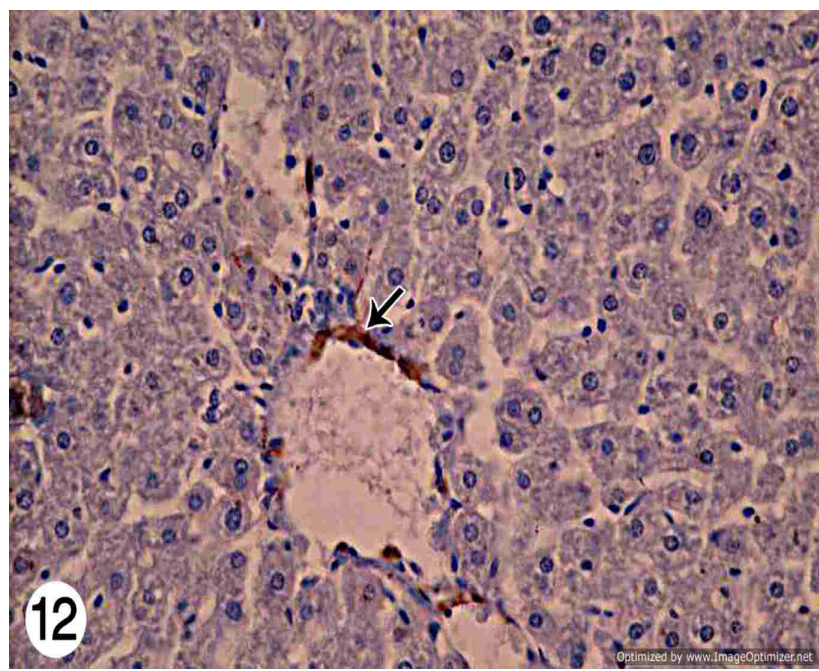

Fig. 12: A photomicrograph of a section in the liver of combined CC14 and GA group showing; mild $\alpha$-SMA staining restricted to the central vein only $(\uparrow)$. $\quad(\alpha$-SMA Immunostaining, X400.).

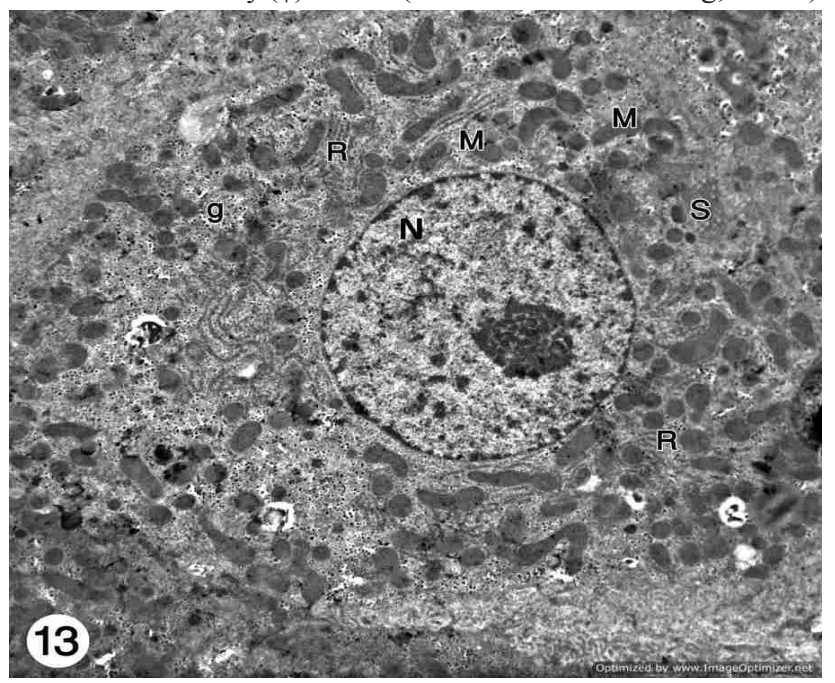

Fig. 13: An electron micrograph a section in liver of control rat showing normal hepatocytes with euchromatic nuclei $(\mathrm{N})$, the cytoplasm contains numerous variable sized mitochondria (M), many rough endoplasmic reticulum (R), SER (S) and numerous glycogen granules $(\mathrm{g})$.

(TEM,

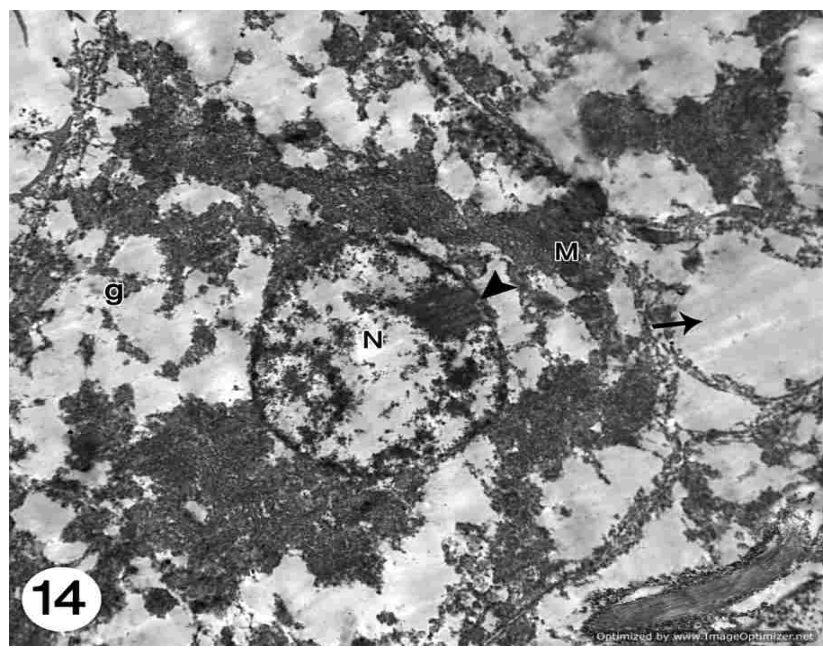

Fig. 14: An electron micrograph of a part of rat liver of CCL4 group showing degenerated electron lucent cytoplasm $(\uparrow)$ which contained with dense organelles, mitochondria (M) and dispersed glycogen granules $(\mathrm{g})$. Notice, the peripheral localization of the nuclear heterochromatin clumps $(\Delta)$ (TEM, X3600). 


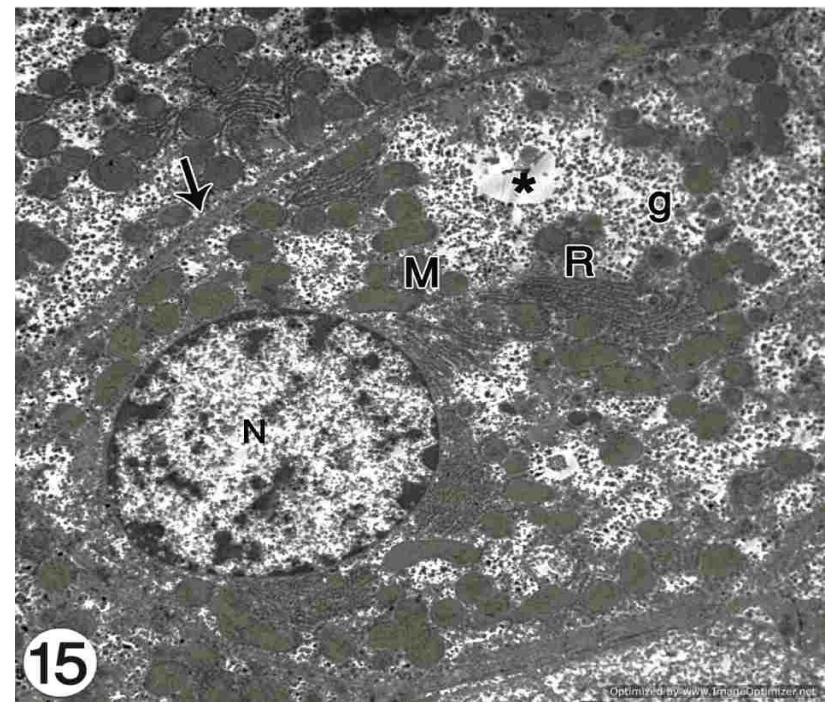

Fig. 15: An electron micrograph a section in liver of combined CCl4-and GA group showing hepatocytes with fine distribution of the chromatin $(\mathrm{N})$, well defined cell membrane $(\uparrow)$, cisterna of rER (R), and numerous mitochondria(M) . Numerous glycogen granules were seen $(\mathrm{g})$. Small electron lucent areas were observed in the cytoplasm $(*)$.

(TEM, X 3600).

\section{DISCUSSION}

Hepatic fibrosis is a serious insult to the liver due to accumulation of extracellular matrix (ECM) proteins, specifically several types of collagen fibers ${ }^{[14]}$. The possible consequences of fibrosis include liver cirrhosis and hepatocellular carcinoma ${ }^{[15]}$.Chronic hepatic injury by carbon tetrachloride is a wellestablished animal model of liver fibrosis ${ }^{[16]}$.

In the present work, histological examination of CCl4-exposed rats showed dilatation and congestion of central vein and blood sinusoid and inflammatory cellular infiltration. Dilatation might be due to increase the level of prostaglandin synthesis that induces smooth muscle relaxation and vasodilatation. Congestion might be resulted from loss of fluid from dilated vessels, so it became filled with $\mathrm{RBCs}^{[17]}$. This was agreed with ${ }^{[18]}$ who mentioned that, in liver injury caused by CCl4, inflammatory processes resulted from products released by activated Kupffer cells. We also observed altered cells with no or dense nuclei and vacuolated cytoplasm in CCL4 group. The vacuolated cytoplasm and the increase in cell volume are due to the loss of regulating mechanism of the cell to pump out water from the inside. Swelling of the cell in CC14 treatment is due to the changed permeability of the cell membrane. Since CCl4 is a nonpolar lipophilic substance this results in the changed physical and chemical characteristics of the lipid membrane of both cytoplasm and mitochondria. This leads to disruption of the $\mathrm{Na}+/ \mathrm{K}+$ pump and migration of interstitial fluids to the hepatocytes ${ }^{[19]}$.

In CCl4 group, we observed that Masson's trichrome stained liver sections clearly showed excess extracellular fibrous materials scattered across the liver especially in the area of portal tracts and central veins. So the treatment of rats with $\mathrm{CCl} 4$ for 8 weeks induced liver fibrosis. Also statistical analysis of collagen area $\%$ showed significant increase in the collagen fibers in CCL4 group. This was explained by ${ }^{[20]}$ who reported that the inflammatory cells released cytokines. These cytokines modulate gene expression in hepatocytes that increase the production of procollagen. They also increase the inhibitors of the collagen breaking down enzyme. So the production of collagen exceeds its breaking down resulting in liver fibrosis.

Alpha-smooth muscle actin ( $\alpha$-SMA) is a good marker for the detection of myofibroblast- like cells in both rat and man. So it is a reliable marker for activated hepatic stellate cells which induce fibrous tissue deposition. Thus, it is a marker for liver fibrosis and useful for monitoring the efficacy of therapy ${ }^{[21]}$.

In the present work ( $\alpha$-SMA) was detected immunohistochemically in liver tissue. In control rats, $\alpha$-SMA expression was restricted to the wall of portal and central veins, while other areas remain negative, suggesting few activated HSCs. This was agreed with ${ }^{[22]}$ who found that administration of $\mathrm{CCl} 4$ caused an apparent increase in the $\alpha$-SMA expression around the portal veins and central vein. They also reported that HSC, which in the healthy liver store vitamin A, undergo a process of activation due to liver damage. Activation was mediated by resident hepatic cell types such as hepatocytes, Kupffer cells and liver endothelial cells.

In the present work electron microscopic examination of sections of CCL4 treated rats showed hepatocellular necrosis, rarified cytoplasm and dark heterochromatic nuclei. The degenerated and granulated cytoplasm contained dispersed glycogen granules with the appearance of many electron lucent areas. This was explained by ${ }^{[23]}$ who indicated that the last stage of cell death affected only individual cells and left the other cells intact. These changes were seen as evidence for apoptosis. This was agreed with $^{[24]}$ who found that CCL4 cause some cells bodies to shrink and lose contact to their neighboring cells, chromatin in nuclei condenses and migrates to the nuclear membrane, and finally the cells were fragmented into membrane-bounded structures, called 'apoptotic bodies. These changes could be resulted from disturbed protein integrity and cell membrane lipid. As with cell degeneration the protein content was watered down and the cell appear clear ${ }^{[25,26]}$ also reported that accumulation of toxic metabolites might cause damage of the cell membrane resulting in hydropic degeneration and vacuolation of hepatocytes.

This was agreed with ${ }^{[27]}$ who mentioned that $\mathrm{CCl} 4$ affect calcium homeostasis. It induces influx of 
calcium into the cytoplasm by disrupting membrane integrity by lipid peroxidation and by opening certain membrane calcium channels. Calcium also could contribute to cell death by the over stimulation of calcium-dependent cellular enzymes that initiate a cascade of events, resulting in irreversible cell injury.

So CCL4 could induce hepatotoxicity by two mechanisms; the first was the production of more reactive free radical attacking microsomal lipids, DNA and proteins in the endoplasmic reticulum resulting in a cascade of lipid peroxidation, cell necrosis and liver fibrosis ${ }^{[28]}$. The second, required activation of CCL4 to produce free radicals which activate Kupffer cells to secrete cytockines that attract and activate neutrophils ${ }^{[20]}$. Also the damage of hepatocytes activates the quiescent stellate cells and transforms them into myofibroblast like cells that play a role in the development of liver fibrosis ${ }^{[29]}$.

Our histological results revealed that Gallic acid cotreatment showed prevention of hepatic lesions. Some hepatocytes were more or less similar to control group. However, other hepatocytes showed variation in the nuclear size. Other hepatocytes showed vacuolated cytoplasm. Some blood sinusoids were also dilated and congested. This was agreed with ${ }^{[25]}$ who found an increase in nucleo-cytoplasmic ratio in states of increased cellular activity which might occur during cell repair.

In the present study, reduction in the liver collagen fiber by Gallic acid was observed. In agreement with these results, ${ }^{[30]}$ attributed these finding to gallic acid content of epigallocatechin, (epicatechin gallate) which has been reported to suppress cell proliferation and collagen production in HSC. So the mechanism of GA in reducing hepatic fibrosis may be closely related to inactivation of HSC. Others explained GA hepatoprotection by selective HSC death with no harm to hepatocytes. Thus GA may represent a potential therapeutic agent to prevent liver fibrosis ${ }^{[31]}$.

In the present work the co-adminstration of gallic acid caused an apparent decrease in the $\alpha$-SMA expression around the portal veins and central vein. This was agreed with ${ }^{[31]}$ who reported that GA selectively killed HSCs in both dose- and timedependent manners, without harm to hepatocytes. They also found that GA toxicity was associated with a rapid burst of reactive oxygen species (ROS) and a subsequent increase of intracellular $\mathrm{Ca}$ activity.

Phenolic hydroxyl groups are known to be potent in scavenging free radicals. The $\mathrm{OH}$ - group at the para position to the carboxylic group is especially effectual for the antioxidant activity. Thus the three hydroxyl groups present in Gallic acid may be responsible for its antioxidant and anti-inflammatory properties ${ }^{[32]}$.
Cytochrome P4502E1 (CYP2E1) protein is an effective generator of reactive oxygen species. in the presence of iron catalysts, it produces powerful oxidants such as the hydroxyl radical. The present study revealed that the Gallic acid could restore the antioxidant functions to near normal. The protective effect of Gallic acid may be attributed to its inhibiting activity on CYP2E1 ${ }^{[33]}$.

Thus gallic acid not only protects the integrity of plasma membrane but at the same time increases the regenerative and reparative capacity of the liver. Gallic acid may directly combine with free radicals and lead to their inactivation which may suppress the intracellular concentration of free radicals. These results suggested that the compound gallic acid efficiently protected the liver from oxidative damage by minimizing cell membrane disturbances and helped in normal functioning of this vital organ. In the present work, we found that hepatic MDA levels were highly significantly increased in $\mathrm{CCl} 4$ treated group. This was agreed with ${ }^{[34]}$ who reported that the increased MDA level suggested increased oxidative stress and lipid peroxidation resulting in tissue damage and failure of antioxidant defense mechanisms in preventing the formation of excessive free radicals. In our studies, the levels of MDA in the Gallic groups were lower than those in CCl4injured group. This suggested that gallic acid could inhibit the peroxidation induced by CCl4. MDA has also been observed in quiescent cells, suggesting that lipid peroxidation might activate HSC and stimulate their fibrogenesis and collagen type I gene transcription. Thus, to control and prevent liver fibrosis greatly depends on controlling activation of HSC. So this indicated that gallic acid decreased the synthesis of ECM by reducing the proliferation and activity of $\mathrm{HSC}^{[35]}$. AST and ALT are the amino transferase in liver cells. They are cytoplasmic in nature, but with liver injury large quantities of these enzymes enter into the circulatory system due to altered permeability of membrane, hepatic necrosis, fibrosis and reduced performance of the liver, which are proportionally to the intensity of cellular damage ${ }^{[36]}$. In the present study CC14 administration leaded to a highly significant increase in the serum levels of ALT and AST. It is also caused significant increase in the serum ALP which may be due to increased synthesis due to increasing biliary pressure. Gallic acid co-administration had significantly lowered plasma AST, ALT and ALP activities, as compared to rats administered $\mathrm{CCl} 4$ only. The low levels of ALT and AST in the gallic acid treated group beyond the control group may indicate that the hepatic parenchyma was at its recovery stage from the injury caused by $\mathrm{CCl} 4$ and the marked loss of hepatocytes ${ }^{[37]}$. GA treatment indicated the effectiveness of the drug in maintaining the functional homeostasis of the liver. The antioxidant activity of GA 
is mainly due to its redox properties. GA, as a strong antioxidant can either scavenge ROS or stimulate detoxification mechanisms within cells, resulting in ROS removal ${ }^{[38]}$.

In the present work we observed a significant increase in the liver content of hydroxyproline in CC14 group compared with the control group while Gallic acid co-administration with CCL4 resulted in a significant decrease in hydroxyproline level compared to rats treated with CCL4 alone. Hydroxyproline was chosen in this work as it is a sensitive marker that increases significantly during liver fibrosis.

GSH is a principle endogenous antioxidant which counterbalances free radical mediated damage and protects the normal cell structure and function by maintaining the redox homeostasis. In the present study there was a highly significant reduction of hepatic GSH content in CCl4 treated group. This was explained by ${ }^{[39]}$ who reported that the decrease could be due to conjugation of GSH with electrophiles whose production increased by the inhibition of enzymes, like glutathione reductase, glutathione peroxidase, glucose-6-phosphate dehydrogenase, which are involved in GSH synthesis and regeneration. Gallic acid co-administration attenuated the decrease in GSH induced by CCL4.

Superoxide dismutase (SOD) is an enzyme that catalyzes the dismutation of superoxide $(\mathrm{O} 2-)$ into oxygen and hydrogen peroxide, so it is an important antioxidant defense in nearly all cells exposed to oxygen. In the present work we observed a significant decrease in the SOD activities of the liver tissue on CCL4 administration. This might indicates a disturbance in free radical levels and thereby an increase in cellular damage. So the amount of free radicals generated and the antioxidants present in the cell are imbalanced. So CCl4 not only initiates lipid peroxidation but also reduces tissue GSH and SOD activities, and this depletion may result from oxidative modification of these proteins. Gallic acid co-administration to CCL4 treated rats significantly increased the SOD activities. This could be due to the free radical scavenging and antioxidant property of Gallic acid ${ }^{[40]}$.

\section{CONCLUSION}

In conclusion, our biochemical and immunohistological results clearly indicate that CCL4- disturbed the cellular integrity of hepatocytes. It also increased the level of oxidative stress by decreasing the antioxidant enzymes. Also, it was found that Gallic Acid has antiinflammatory and antioxidant activity, associated with decreasing the synthesis of ECM by suppressing the activation of $\mathrm{HSC}$
So it may be useful to use Gallic Acid as an adjunctive supplementation to protect liver and minimize its damage. It may be used as a therapeutic and preventive measure against hepatic fibrosis

\section{CONFLICT OF INTEREST}

The authors have no conflicting financial interest.

\section{REFERENCES}

1. Liu HL, Li HX, Wang YD, Yang SP. Matrix metalloproteinase-2 and tissue inhibitor of metalloproteinase-1 expression in fibrotic rat liver. World J. Gastroenter. 2000; 6(6), 881-884.

2. Wernke MJ, Schell JD. Solvents and malignancy, Clinics in Occupat. Environment. Med. 2004; 4 (3): 513-527.

3. Smyth R, Munday MR, York MJ, Clarke CJ, Dare T, Turton JA. Comprehensive characterization of serum clinical chemistry parameters and the identification of urinary superoxide dismutase in a carbon tetrachloride-induced model of hepatic fibrosis in the female Hanover Wistar rat. Int. J. Exp. Pathol. 2007; 88: 361-376.

4. Uzma L, Hadiya H, Devoshree M, Riaz A . Hepatoprotective efficacy of gallic acid during Nitrosodiethylamine-induced liver inflammation in Wistar rats. The J. Basic \& Applied Zool. 2016; 76: 31-41.

5. Kris-Etherton PM, Hecker KD, Bonanome A, Coval SM, Binkoski AE, Hilpert KF, Griel AE, Etherton TD. Bioactive compounds in foods: their role in the prevention of cardiovascular disease and cancer. Am. J. Med. 2002; 113: 71-88.

6. Abella A, Chalas J. Antioxidant activity of phenolic acids and esters present in red wine on human LowDensity Lipoproteins. Atheroscler. 1997; 134: 199206.

7. Mämmelä P, Savolainenb H, Lindroosa L, Kangasd $\mathrm{J}$, Vartiainen T. Analysis of oak tannins by liquid chromatography- electrospray ionisation mass spectrometry. J. Chromatography 2000; 891:75-83.

8. Borde VU, Pangrikar PP, Tekale SU. Gallic acid in Ayurvedic herbs and formulations. Recent Res. Sci. Tech. 2011; 3: 51-54.

9. Manach C, Williamson G, Morand C, Scalbert A: Bioavailability and bioefficacy of polyphenols in humans. I. Review of 97 bioavailability studies. Am. J. Clin. Nutr. 2005; 81 (suppl.):230S-42S. 
10. Shaker M, Zalata K, Mehal W, Shiha G, Ibrahim T. Comparison of imatinib, nilotinib and silymarin in the treatment of carbon tetrachloride-induced hepatic oxidative stress, injury and fibrosis. Toxicol. Appl. Pharmacol. 2011; 15; 252(2):165-175

11. Anunkaorn M, Patchareewan P, Bunkerd K and Upa K. Roselle Extract and Gallic Acid Improve Vascular Reactivity of Diabetic Rats. Srinagarind Med. J.2010; 25:257-261.

12. Reitman S, Frankel S. A colorimetric method for the determination of serum glutamic oxaloacetic and glutamic pyruvic transaminases. Amer. J. Clin. Path. 1957; 28: 56-63.

13. Nelson D, Cox M. Lehninger's Principles of Biochemistry, 4th Edition, W. H. Freeman and Company, New York 2005.

14. Wallace K, Burt A, Wright M. Liver fibrosis. Biochem. J. 2008; 411:1-18.

15. Tipoe $\mathrm{G}$, Leung $\mathrm{T}$, Liong $\mathrm{E}$, Lau $\mathrm{T}$, Fung $\mathrm{M}$. Epigallocatechin-3- gallate (EGCG) reduces liver inflammation, oxidative stress and fibrosis in carbon tetrachloride $(\mathrm{CCl} 4)$ induced liver injury in mice. Toxicol. 2010; 273 (1-3): 45-52.

16. Ou Y, Zheng S, Lin L, Jiang Q. protective effect of C-Phycocyanin against carbon tetrachloride induced hepatocyte damage in vitro and in vivo. Chem. Biol. Interact. 2010; 185: 94-100.

17. Walter JB, Israel M. Inflammation. In: Walter JB, Talbot IC, editors. Walter and Israel general pathology. 7th ed.,Churchill Livingstone, New York. 1996; p. 167.

18. Orfi la C., Lepert JC, Alric L, Carrera G, Beraud M, PipyB. Immunohistochemical distribution of activated nuclear factor kappaB and peroxisome proliferatoractivated receptors in carbon tetrachlorideinduced chronic liver injury in rats. Histochem. Cell Biol. 2005; 123: 585-593.

19. Serviddio G, Bellanti F, Vendemiale G, Altomare E. Mitochondrial dysfunction in nonalcoholic steatohepatitis. Expert. Rev. Gastroenterol. Hepatol. 2011; 5: 233-244.

20. Geraci JP, Mariano MS. Radiation hepatology of the rat: Parenchymal and nonparenchymal cell injury. Radiat. Res. 1993; Nov, 136 (2):205-213.

21. Carpino G, Morini S, Corradini S. Alpha-SMA expression in hepatic stellate cells and quantitative analysis of hepatic fibrosis in cirrhosis and in recurrent chronic hepatitis after liver transplantation. Dig. Liver Dis. 2005; 37: 349-356
22. Dong M, Jia Y, Zhang Y, Li C, Geng Y, Zhou L, Li $\mathrm{X}$. Emodin protects rat liver from CCl4-induced fibrogenesis via inhibition of hepatic stellate cells activation. World J. Gastroenterol. 2009; October 14, 15(38): 4753-4762.

23. Xu L, Gao J, Wang Y, Yu W, Zhao X, Yang X. Myrica rubra extracts protect the liver from CCl4-induced damage. Evidence-Based Complementary and Alternative Med. 2011; 1-8.

24. Doon, Cotter T. Morphological assessment of apoptosis. Methods 2008; 44: 200-204.

25. Frost JK. Pathologic processes affecting cells from inflammation to cancer. In: Bibbo $\mathrm{M}$, editor. Comprehensive cytopathol., WB Saunders 1987; p. 68-83.

26. Dixon MF, Dixon B, Aparicio SR and Loney DP. Experimental paracetamol-induced hepatic necrosis: A light and electron -microscope and histochemical study. J. Pathol. 1975; May,116 (1):17-29.

27. Zowail M, Waer H, Eltahawy N, Khater E, Abd El-hady A. Curative Effect of Bone Marrow Cells Transplantation and/or Low Dose Gamma Irradiation on Liver Injuries Induced by Carbon Tetrachloride. The Egypt. J. Hospital Med. 2012; 46: 96 - 114.

28. Vulimiri S, Berger A and Sonawane B. The potential of metabolomic approaches for investigating modes of actions of xenobiotics: case study with carbon tetrachloride. Mutat. Res. 2011; 722: 147-153.

29. Senoo H. Structure and function of hepatic stellate cells. Med.Electron.Microsc. 2004; Mar, 37(1):3-15.

30. Cheung PY, Zhang Q, Zhang YO, Bai GR, Chia M, Lin M. Effect of WeiJia on carbon tetrachloride induced chronic liver injury. World J. Gastroenterol. 2006; 12(12): 1912-1917.

31. Hsieh SC, Wu CH, Wu CC, Yen JH, Liu MC, Hsueh $\mathrm{CM}$, Hsu SL. Gallic acid selectively induces the necrosis of activated hepatic stellate cells via a calcium-dependent calpain I activation pathway. Life sci. 2014 ; 102: 55-64.

32. Shahrzad S, Aoyagi K, Winter A, Koyama A, Bitsch I. Pharmacokinetics of gallic acid and its relative bioavailability from tea in healthy humans. J. Nutr. 2001; 131:1207-10.

33. Tung $\mathrm{Y}$, Wub J, Huang $\mathrm{C}$, Peng $\mathrm{H}$, Chen $\mathrm{Y}$, Yang $\mathrm{S}$. Protective effect of Acacia confusa bark extract and its active compound gallic 3 acid against carbon tetrachloride-induced chronic liver injury in rats. Food and Chemical Toxicol. 2009; 3:21-27. 
34. Kim H, Kim J, Choi J, Jung J, Oh W. Hepatoprotective effect of pinoresinol on carbon tetrachloride-induced hepatic damage in mice. J. Pharmacol. Sci. 2010; 112(1):105-112.

35. Kawada N, Seki S, Inoue M, Kuroki T. Effect of antioxidants, resveratrol, quercetin and $\mathrm{N}$-acetylcysteine, on the functions of cultured rat hepatic stellate cells and Kupffer cells. Hepatol. 1998; May, 27(5):1265-1274.

36. Ahmad A, Ahmad R. Resveratrol mitigates structural changes and hepatic stellate cell activation in N0Nitrosodimethylamine induced liver fibrosis via restraining oxidative damage. Chem. Biol.Interact. 2014; 221: 1-12.

37. Gao H, Li G, Lou M, Li X, Wang J. Hepatoprotective effect of Matrine salvianolic acid B salt on Carbon
Tetrachloride-Induced Hepatic Fibrosis. J. Inflammat. 2012; 9:16-22.

38. Inoue M, Suzuki R, Koide T, Sakaguchi N, Ogihara Y, Yabu Y. Antioxidant, gallic acid, induces apoptosis in HL-60 RG cells. Biochem. Biophys. Res. Commun. 1994; 204: 898-904.

39. Pushpakiran G, Mahalakshmi K, Anuradha C. Protective effects of taurine on glutathione and glutathione-dependent enzymes in ethanol-fed rats. Pharmazie. 2011; 59(11): 869-872.

40. Shahid S, Shamim S ,Mahboob T. Protective effect of green tea on $\mathrm{CCl} 4$ induced hepatotoxicity in experimental rats. African J. Pharmacy and Pharmacol. 2012; 6(26): 1958-1963. 